\title{
Arte plumaria en el siglo XIX: el Emblema Nacional, un nuevo motivo iconográfico para el México republicano
}

Plumarian art in the 19th century: the National Emblem, a new iconographic motive for Republican Mexico

\author{
Montserrat A. Báez Hernández1 \\ ${ }^{1}$ Posgrado en Historia del Arte, Universidad Nacional Autónoma de México (montse_baez@hotmail.com)
}

RESUMEN: El arte plumaria, manifestación artística de origen prehispánico, continúa maravillando tanto por la delicadeza de su materia prima como por el altísimo grado de perfección alcanzado por los amantecas, artífices de la pluma. Las plumas eran consideradas en el México prehispánico un material precioso revestido de simbolismo estético y religioso, íntimamente ligado a la vida espiritual y ritual. El amantecayotl, la fina técnica de mosaico plumario que llegó a la cúspide de su perfección en el siglo XVI, continuó floreciendo tras la caída de Tenochtitlan y durante la dominación española, aunque para el siglo XIX únicamente sobrevivió en pequeños núcleos de producción circunscritos al occidente mexicano. El propósito de este artículo es llamar la atención sobre la supervivencia de esta manifestación artistica en el siglo XIX a través de un primer acercamiento tecnológico e iconográfico a una pieza producida en dicha centuria. Asimismo, se propone la revaloración de los objetos plumarios decimonónicos, cuyo estudio se encuentra aún pendiente en la Historia del Arte en México.

PALABRAS CLAVE: Arte plumaria, Plumas, Siglo XIX, Alegoría, República mexicana.

\begin{abstract}
The ars plumaria, artistic manifestation born in the prehispanic period, continues to astound because of the delicacy of feathers and the high degree of perfection achieved by amantecas. Feathers were considered in Mexico's prehispanic past a precious material related to aesthetic and religious symbolism, closely linked to the spiritual and ritual life. The amantecayotl, the technique of making mosaics with feathers, reached its peak of perfection in the sixteenth century and continued to flourish after Tenochtitlan's conquest and during the Spanish domination, although during the nineteenth century only survived in small nuclei of production. The purpose of this article is to draw attention to the survival of ars plumaria in the nineteenth century through a first rapprochement to the Emblema nacional exploring its material features and iconographic motif. Also, it is proposed the revaluation of ars plumaria objects produced during the nineteenth century, whose study is still pending in the History of Art in Mexico.
\end{abstract}

KEY WORDS: Ars plumaria, Feathers, Nineteenth century, Allegory, Mexico. 
Consideradas como "la sombra de los dioses", las plumas estaban presentes en una gran variedad de ricos ornamentos corporales y atavíos, testimonios de su uso que se han conservado a través de los siglos por medio de los códices, la pintura mural y la cerámica ritual1.

El uso de las plumas con fines estéticos y asociadas a significaciones espirituales estuvo presente en toda Mesoamérica, pero floreció especialmente con gran riqueza en el Altiplano Central de México, en el Imperio mexica durante el reinado de Ahuizotl (1482-1502), convirtiéndose, en el gobierno de Moctezuma II (1502-1520), en un arte cortesano de producción mexica por excelencia (Magaloni-Kerpel, 2006). El amantecayotl, la fina técnica de mosaico plumario que llegó a la cúspide de su perfección en los talleres de México, Tlaxcala, Tzintzuntzan y Pátzcuaro, fue altamente valorado a la llegada de los españoles (Estrada de Gerlero, 2011, p.381), lo que propició el envío de innumerables ejemplares a Europa, así como la producción de nuevos objetos asociados a las funciones litúrgicas del cristianismo tales como mitras, tapacálices y altares portátiles, finas piezas que se conservan en diversas colecciones europeas. Actualmente se conocen únicamente siete ejemplares producidos antes del contacto español: Quetzalcuexyo Escudo de piel de ocelote del Museo Nacional de Historia INAH; dos Xicalcoliuhqui Chimalli Escudos de grecas del Museo Regional de Wüttenberg, Stuttgart; el "tapacáliz" del Museo Nacional de Antropología INAH; el icónico Penacho del México antiguo, un Chimalli con un cánido emplumado y el mosqueador o Abanico de la mariposa, en el Weltmuseum de Viena (Moreno, 2014, p. 118).

La técnica continuó su auge tras la caída de Tenochtitlan y durante la dominación española, siendo uno de sus principales centros productores la Escuela de Artes San José de los Naturales, adscrita al convento de San Francisco el Grande y fundada por el franciscano fray Pedro de Gante (Estrada de Gerlero, 2011, p. 393). Durante el siglo XVIII, el arte plumaria experimentó variaciones en la técnica y la forma de construir los motivos, así como la inclusión de otros materiales como los rostros realizados con pintura al óleo y la aplicación de hoja de oro. Originalmente utilizada para producir objetos suntuarios revestidos o asociados con profundos significados espirituales - ya fuera del mundo prehispánico o cristiano-, para el siglo XIX sobrevivió en pequeños núcleos de producción circunscritos al occidente mexicano e integrando nuevos materiales e iconografías lejanas a las funciones de los siglos precedentes.

\section{Arte plumaria del siglo XIX: memoria y olvido}

El Emblema Nacional, [1], composición realizada con plumas y cera de campeche, forma parte de la colección permanente del Museo Nacional de Antropología del Instituto Nacional de Antropología e Historia de la Ciudad de México. Este recinto fue inaugurado el 17 de septiembre de 1964 y en su discurso museológico fue considerada una amplia sección destinada a exponer la riqueza etnográfica de los pueblos originarios de México, denominada como salas Etnográficas. El Emblema forma parte de la colección permanente de la sala Puréecherio presente en esta área.

\footnotetext{
${ }^{1}$ Los resultados de este primer acercamiento se presentaron en el marco del curso Plumaria de México, arte y tecnología, impartido por la Dra. María Olvido Moreno Guzmán en el Posgrado en Historia del Arte de la Universidad Nacional Autónoma de México, otoño de 2015. Agradezco el apoyo tanto de la Dra. Moreno como de la Lic. Samira Macías Flores, quien me proporcionó información sobre la intervención y estado de la pieza.
} 
La ficha del objeto nombra a José Rodríguez como autor del Emblema y señala que fue elaborado en 1824 para conmemorar el establecimiento del primer Congreso de la Unión en México. Asimismo, el catálogo en línea del MNA consigna su probable producción en Pátzcuaro, Michoacán, lo que justifica su inclusión en el área Puréecherio (Rodríguez). La pieza fue elaborada con plumas de varias especies de aves unidas al soporte por medio de cera de campeche y está enmarcada con vidrio y un marco de madera. Sus dimensiones son $105 \mathrm{~cm}$ de alto por $74 \mathrm{~cm}$ de ancho, con $1.2 \mathrm{~cm}$ de espesor (Rodríguez).

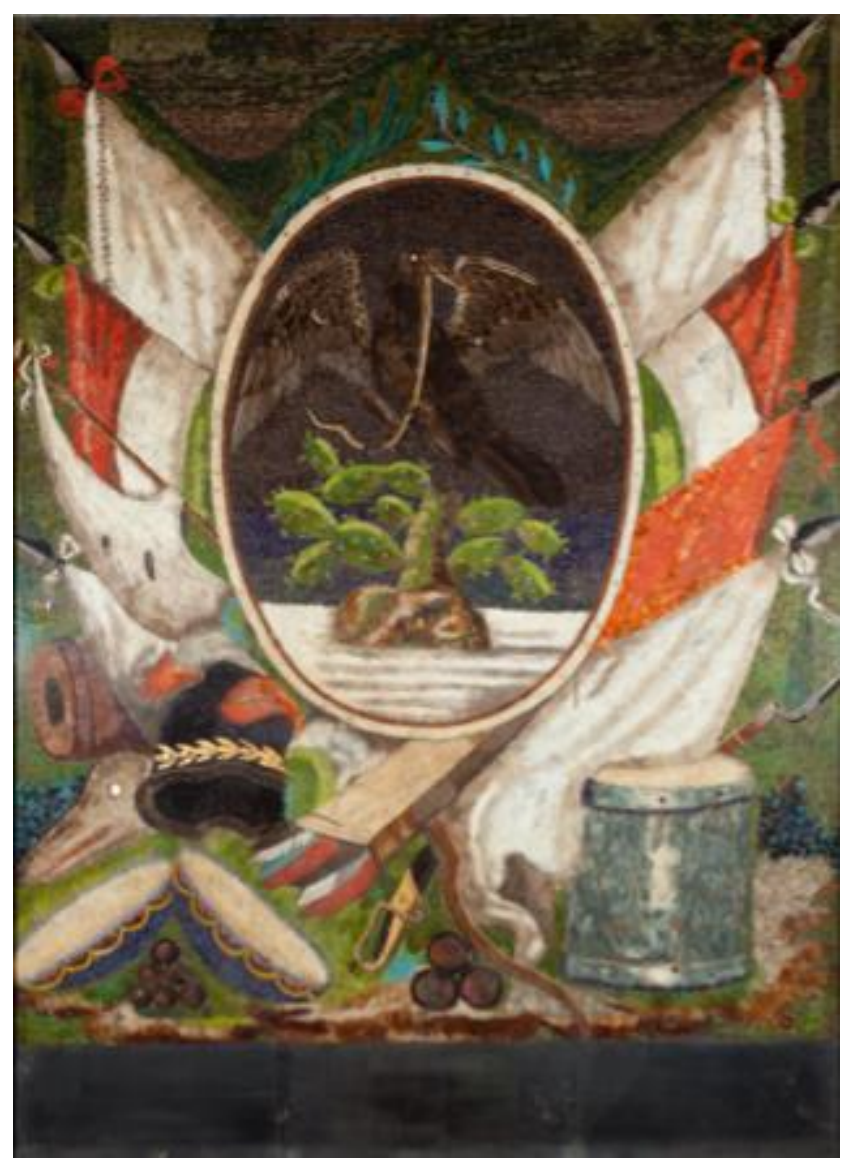

1. Emblema Nacional, José Rodríguez, 1824

Plumas sobre cera de campeche, $105 \times 74 \mathrm{~cm}$ Museo Nacional de Antropología, INAH.

A diferencia de los ejemplares de arte plumaria elaborados durante los siglos XVI y XVIII que cuentan con numerosos estudios especializados, tanto en su dimensión histórica como material, la historiografía no proporciona información que permita conocer el desarrollo de las piezas producidas a partir de 1800, salvo algunas noticias aisladas que denuncian la pérdida de la técnica. Ya desde finales del siglo XVIII, Francisco Javier Clavijero refirió su desaparición (1826, p. 375):

"Poco tiempo ha vivía en Pazcuaro, capital del reino de Michuacan, donde más que en ninguna otra parte floreció el arte de que vamos hablando, el ultimo artífice de mosaico que quedaba, y con él habrá acabado o estará para acabar un ramo tan precioso aunque hace dos siglos que no se cultiva con la perfección que supieron darle los antiguos".

Clavijero, además, aportó un juicio sobre la plumaria superviviente al afirmar que ya no poseía la calidad de los trabajos antiguos, lo que confirma que para la época existían modificaciones 
sustanciales en la técnica. A su vez, otros viajeros y autores del siglo XIX como Alexander von Humboldt, Jules Leclerg y Frances Calderón de la Barca también señalaron en sus crónicas la pervivencia de la técnica, aunque, a diferencia de Clavijero, admiraron la gran calidad y "rara belleza" de los mosaicos elaborados en Michoacán (Sereno, 2013, p. 34). En El museo mexicano ó miscelanea pintoresca de amenidades curiosas e instructivas, obra colectiva publicada en 1843 con el objetivo de conservar para los mexicanos ilustrados "los descubrimientos asombrosos que se han hecho en las ciencias y en las artes, y datos preciosos-sobre las antigüedades misteriosas de nuestro país" (1843, p. 4), dedicó un apartado al Mosaico de plumas siguiendo las noticias del jurista y explorador italiano Giacomo Constantino Beltrami, quien los consideró adornos de lujo y obras "de mucha curiosidad" (1843, p. 272).

Finalmente, Carlos María de Bustamante, historiador oaxaqueño, al igual que los cronistas antecesores, llamó la atención sobre el alto costo de los trabajos plumarios realizados en Pátzcuaro debido a los pocos artistas plumajeros que continuaban realizando su arte a principios del siglo XIX. En sus notas de 1829 a la Historia general de las cosas de la Nueva España de fray Bernardino de Sahagún, da la primera noticia documental del Emblema Nacional (Sahagún, 1829, p. 387):

"El más sobresaliente en este árte en estos últimos tiempos fue un José Rodriguez, el cual presentó al primer Congreso General un cuadro con las armas de la República mexicana rodeada de trofeos, y en remuneración de obra tan particular, el Supremo Gobierno le gratificó con ochocientos pesos, a solicitud particular mía dirigida al Congreso general".

Bustamante señaló que el 4 de octubre de 1829 se presentó dicho “escudo” en el balcón principal de la Ciudad de México con motivo de la derrota del brigadier Isidro Barradas por los generales Antonio López de Santa Anna y Manuel Mier Terán. La batalla conocida como La victoria de Tampico, suscitada el 11 de septiembre de 1829, significó un intento de la corona española por recuperar México, tras su declaración de independencia el 27 de septiembre de 1827. Gracias a dicha nota es posible afirmar que la creación del Emblema se circunscribió a un móvil político de propaganda para la nueva república.

Además de las noticias dadas por Bustamante, hasta el momento no se ha podido rastrear información biográfica que permita caracterizar en profundidad a José Rodríguez, el autor del Emblema nacional, por lo que únicamente es posible incluirlo entre los nombres de los artistas plumajeros activos que la historiografía consigna en la región de Michoacán durante el siglo XIX: Inocencio Victoria, Mariano Lagarroiti, Adalberto Mengosa (Castelló Yturbide, 1993, p. 215), Urbano Jáuregui y Mónico Guzmán Álvarez (Sereno, 2013, pp. 30-34).

\section{El Emblema nacional: un nuevo motivo iconográfico para la patria republicana}

El Emblema nacional consta de una composición central en la que los objetos se ordenan alrededor de un óvalo coronado por hojas de encina y laurel que encierra un águila sobre un nopal devorando una serpiente [2]. Alrededor del óvalo se agrupan ocho banderas, mientras que en la parte inferior se ordenan, a la derecha un tambor y la punta de una bayoneta; en el centro un carcaj, el mango de una espada y tres balas de cañón; y a la izquierda más balas, un par de timbales, un gorro frigio, la cabeza de un caimán y la boca de un cañón. 


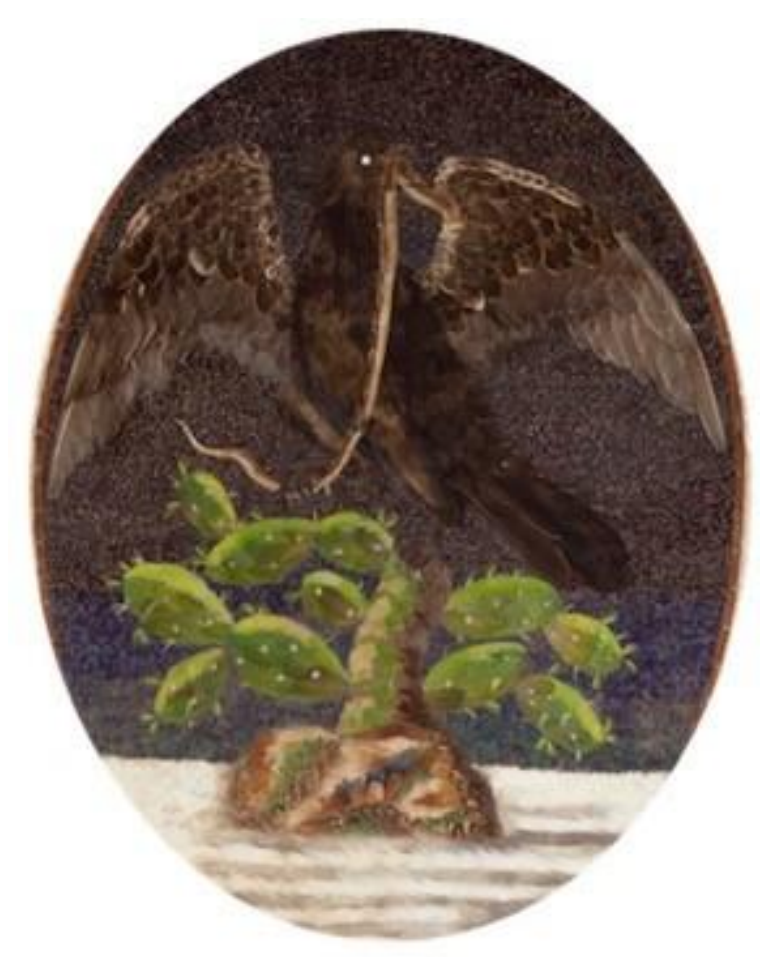

2. Emblema Nacional (detalle), José Rodríguez, 1824.

Plumas sobre cera de campeche, 105 x $74 \mathrm{~cm}$, Museo Nacional de Antropología INAH.

Acerca del título de la pieza, más que un emblema cuya definición supone la presencia de un texto que posea correspondencia con una imagen o pictura, y un lema o mote (Sebastián, 1994, p. 57), — elementos ausentes en este caso-- esta composición se trata de una alegoría, es decir, la representación simbólica de ideas abstractas por medio de grupos de figuras (Fatás, 2006, p. 17). Esta alegoría procede de la tradición grecolatina revalorada en el siglo XIX y que, a través de símbolos heredados de la cultura emblemática vigente en el periodo novohispano, logró representar el territorio, la patria o el Estado, materializando el concepto abstracto en una imagen visible, rodeada de atributos significativos (Florescano).

Este tipo de composición que muestra un elemento central, rodeado por otros elementos bélicos que lo enmarcan, está relacionado con los "trofeos" de la Antigüedad Clásica. En Grecia, el trofeo representaba el poder militar y la victoria ante el enemigo, se elaboraba con los restos del armamento de los vencidos, y se colgaba de un tronco o se amontonaba en el campo de batalla. Los romanos retomaron dicha tradición y, a su vez, los integraron como símbolo de victoria en los arcos de triunfo, monedas y columnas ornamentadas (Ramon i Navarro, 2011, p. 48).

El concepto de trofeo, ya como monumento erigido con armaduras, armas y enseñas militares, fue recuperado en el Renacimiento para representar la victoria. En los siglos XVI Y XVII, se utilizó como un ornamento formado por armas, escudos, lanzas y banderas, dispuestos según un canon de belleza en las paredes de los salones nobiliarios como continuación del trofeo militar. Finalmente, en el siglo XVIII, como consecuencia de las exploraciones de la ciudad de Herculano, Italia, y publicaciones como Observations sur les antiquités de la ville d'Herculaneum (1754) de Jacques Germaine-Souffot, y las obras de Giovanni Battista Piranesi Della Magnificenza (1761) y Parere sull'architettura (1765), los cánones clásicos se revalorizaron en las artes bajo el llamado Neoclasicismo. Los trofeos, como parte de este repertorio, reaparecieron como elementos 
ornamentales, desprovistos de su significado militar para convertirse en símbolos de la victoria en las artes, el amor, las ciencias y otras disciplinas. Por ello, a partir de la segunda mitad del siglo XVIII, circularon una gran cantidad de cahiers de trophées que presentaban, a manera de catálogo, diferentes tipos de trofeos ornamentales. Un ejemplo de ello es el Premier cayer de trophées utiles a toutes sortes d'ouvrages (1766), en el que se aprecia un trophée de guerre cuya composición es muy similar al del Emblema nacional: en torno a un escudo coronado se ordenan varios lábaros, mientras en el suelo hay cañones y otras armas [3]. Además de los elementos militares del Emblema, hay algunos elementos que no proceden del motivo grecolatino, sino que se pueden rastrear a partir de la segunda fuente propuesta para el estudio de la pieza: la tradición emblemática.

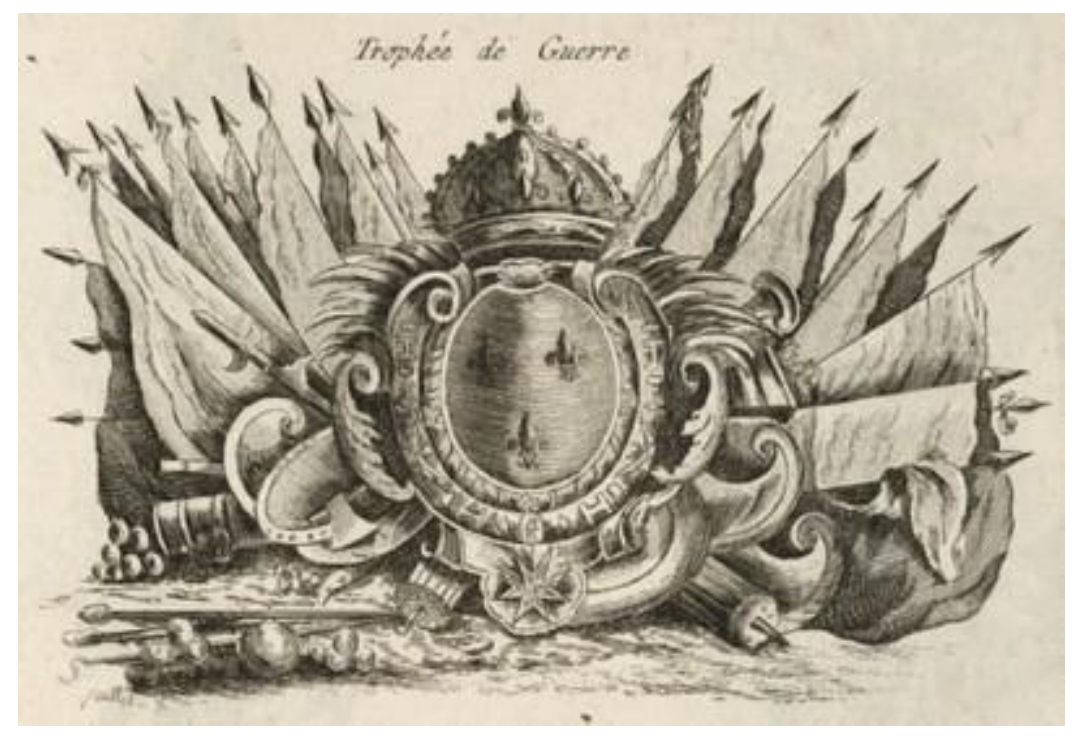

3. Trophée de guerre, Jacques Juillet, 1768.

Fuente: Ier Cayer de Trophées utiles a toutes sortes d'ouvrages. Se vendent a Paris chez Juillet Graveur rue des rats vis a vis la rue des Portes Place Maubert, p. I. Bibliothèque de l'Institut National d'Histoire de l'Art, collections Jacques Doucet.

La presencia del caimán, el carcaj y los timbales, ajenos a la Antigüedad Clásica, se pueden reconocer en la alegoría de América descrita por Cesare Ripa en su Iconología (1593), donde la caracteriza como: "Mujer desnuda y de color oscuro [...] con la izquierda ha de sostener un arco, y una flecha con la diestra, poniéndosele al costado un carcaj bien provisto de flechas [...] al otro lado se pintará un lagarto o caimán..." (Ripa, 2007, pp. 108-109). Esta imagen, aunque de connotación negativa asociada a lo salvaje, fue ampliamente utilizada en la Nueva España durante los siglos XVI al XIX en representaciones artísticas relacionadas con lo americano; llegando al punto de convertirse -hasta el siglo XIX- en el arquetipo de América (Roque, 1994, pp. 1020-1022). Tras la Independencia de México consumada en 1821, surgió una búsqueda de una identidad nacional que se vería reflejada en el arte por medio de la recuperación del pasado prehispánico pero, también, reapropiándose del vocabulario conceptual de imágenes adoptado por la cultura novohispana y adaptada a las exigencias representativas de la nueva nación (Acevedo, 2000, p. 115). Por tanto, América representada alegóricamente como una mujer joven portando el águila, la bandera mexicana y armas como atributos que simbolizaban a la nueva nación, fue muy frecuente en el siglo XIX; sin embargo, después de este primer momento, tras la caída del Primer Imperio (1821-1823) y la instauración de la República Federal en 1823, este lenguaje alegórico sufrió modificaciones que revelan una tercera influencia procedente de la iconografía revolucionaria francesa. 
Francia fue considerada por los pensadores y políticos mexicanos como el paradigma de la patria liberal y, por tanto, el modelo a seguir para alcanzar una "república federal no heredera del Anáhuac o de la Nueva España, sino de la Revolución Francesa y de la Insurgencia de 1810" (Florescano, 2006, p. 239). Las representaciones de la nación a partir de este punto se vieron influenciadas por los elementos de la iconografía francesa: las banderas, el gorro frigio símbolo de la liberalidad republicana y las armas como la espada, el fusil con bayoneta y el cañón con balas, referentes de la lucha bélica por la libertad. Cabe señalar que la iconografía revolucionaria francesa, a su vez, también procede de una reinterpretación de los símbolos de la monarquía retomados de la antiguiedad grecolatina, como por ejemplo, los trofeos usados en las Lettres patentes du roi y otros documentos oficiales emitidos durante el gobierno de Luis XVI [4].

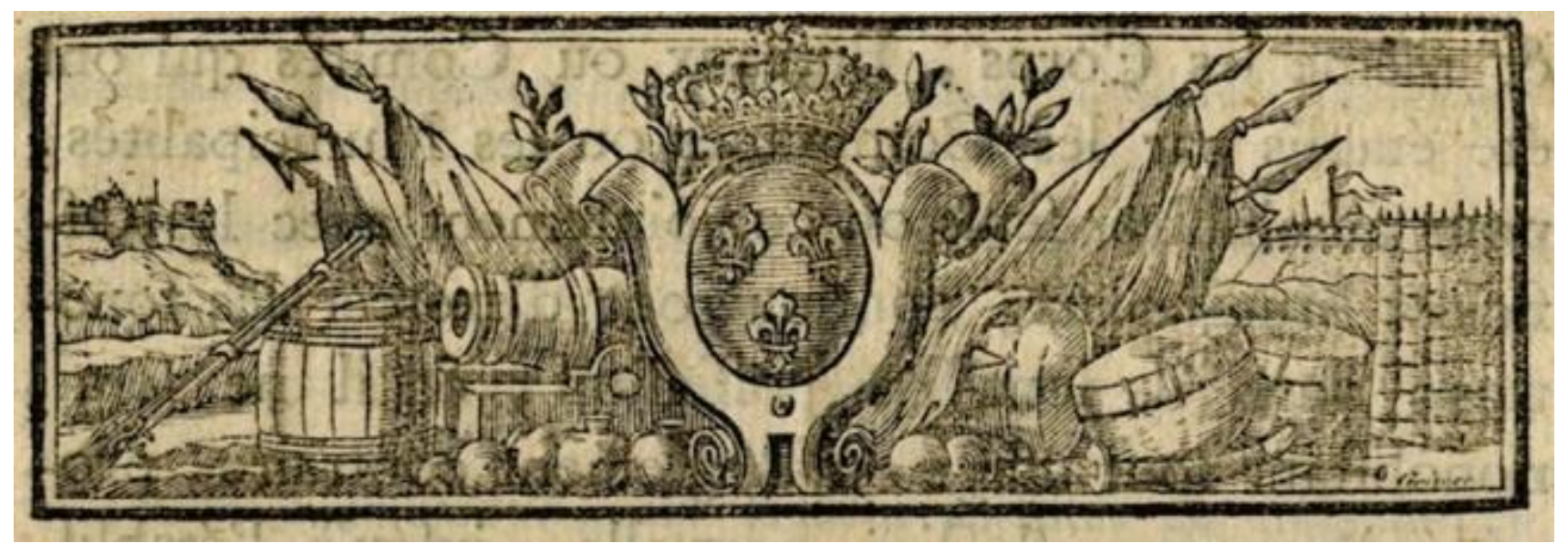

4. Encabezado con trofeo de guerra, 1789.

Fuente: Lettres-patentes du roi, sur un décret provisoire de l'Assemblée nationale concernant les municipalités, Paris, Chez Daumon, Imprimeur du Roi \& du parlement, Place de Gramont. University of Maryland, College Park.

El Emblema nacional, siguiendo la noticia de Bustamante que indica que fue elaborado con motivo del primer Congreso de la Unión en 1824, se circunscribe a la producción artística de la República Federal que buscaba generar una nueva imagen de nación. Por tanto, el óvalo central ya muestra el "Escudo de la Primera República" estipulado por el Decreto del 14 de abril de 1823. Escudo de armas y pabellón nacional (Rodríguez de san Miguel, 1839, p. 2):

“1. Que el escudo sea el águila mexicana parada en el pie izquierdo sobre un nopal que nazca de una peña entre las aguas de la laguna y agarrando en el derecho una culebra en actitud de despedazarla con el pico; y que orlen este blasón dos ramas, la una de laurel y la otra de encina, conforme al diseño que usaba el gobierno de los primeros defensores de la independencia.

2. Que en cuanto al pabellón nacional se esté al adoptado hasta aquí, con la única diferencia de colocar el águila sin corona, lo mismo que debe hacerse en el escudo".

Por tanto, el Emblema conjuga los símbolos de tradición grecolatina: la composición tipo trofeo; el lenguaje emblemático novohispano en los atributos de la alegoría de América; y por último la iconografía revolucionaria francesa -el gorro frigio, las armas y nuevamente la composición en trofeo tomada de los símbolos monárquicos reapropiados-. Todas estas influencias se unieron para enmarcar 
el escudo nacional decretado por el congreso, uno de los nuevos símbolos de la República Federal. Este tipo de alegorías nacionales alcanzaron gran impacto como imágenes del nuevo régimen y su elaboración — con algunas variantes - se extendió hasta finales del siglo XIX. Presentes en relieves de edificios gubernamentales, pintadas en banderas y lábaros, también fueron pintadas compartiendo la composición y la repetición de elementos iconográficos como Alegoría de Miguel Hidalgo, pintada por F. Flores en 1882 y Alegoría del Escudo Nacional, de V. Jiménez en 18782.

Por último, se pueden citar otros ejemplos de alegorías nacionales elaboradas en plumaria y fechables también en el segundo tercio del siglo XIX debido a la configuración del escudo en el decreto antes mencionado: Escudo Nacional de la época juarista con gorro frigio, presente en el Museo Nacional de Morelia (Moreno, 1993, p. 235); y el Escudo Nacional que se conserva en el Museo Übersee de la ciudad de Bremen. La existencia de estos ejemplares plantea que este motivo, además de circular como una imagen de la nueva nación, era potencializado como símbolo al estar elaborado en la técnica plumaria heredada del glorioso pasado prehispánico.

\section{Un acercamiento a la técnica de manufactura}

El Emblema nacional formó parte de las obras elegidas para la exposición temporal El vuelo de las imágenes. Arte plumario en América y Europa del año 2011, organizada en conjunto con el Instituto Nacional de Antropología e Historia y el Museo Nacional de Arte INBA. A partir de su selección, fue examinada para determinar su estado material y, a partir de ello, la pertinencia de su exhibición3.

Respecto a los materiales de elaboración, Carlos María de Bustamante refirió en sus noticias sobre el Emblema que el artífice utilizó "el secreto de untar la pluma antes de pegarla para librarla de la polilla [...] con una raíz llamada tacinguis que se halla en Pátzquaró según me dijo" (Sahagún, 1829, p. 397). Este mucílago, cuyo nombre en lengua purépecha tatzingueni significa "engrudo", procede de la Posthechea citrina, especie de orquídea mexicana que se distribuye principalmente en la zona media del país, en estados como Durango, Jalisco, Nayarit, Veracruz, Oaxaca, Guerrero y Michoacán (Núñez, 2014, p. 83). Aunque Bustamante lo considera una "novedad", el uso del tatzingueni, específicamente el tzauhtli, mucílago de orquídea Epidendrum pastoris y Laelia autumnalis (Román, 2006, p. 67), como adhesivo e insecticida natural para la plumaria está documentado desde el Códice Florentino de Bernardino de Sahagún, quien lo nombra tlauhtli (Estrada de Gerlero, 2011, p. 384). Ya que la pieza no requirió de intervenciones a nivel estructural o químico, no fue posible constatar en ella el uso del mucílago de orquídea.

En la actualidad, el Emblema nacional se muestra resguardado en un marco de madera y cubierto por cristal en las salas Etnográficas del Museo Nacional de Antropología, lo que, de acuerdo con los planteamientos para su intervención por parte del equipo del Laboratorio de Conservación, permitió su restablecimiento en el discurso museográfico (Macías y Blas, 2012).

\footnotetext{
${ }^{2}$ Como dato al margen, en el Inventario: lienzos, cuadros y retratos que posee la Escuela en el año de 1895 de la Escuela Nacional de Bellas Artes, se consigna un Escudo con las armas nacionales elaborado por José Corral en el siglo XIX y avaluado en 1,000 (Báez, 2003, p. 419), lo que revela el éxito de la hechura de dichas composiciones.

${ }^{3}$ La licenciada en Restauración, Samira Macías Flores, quien intervino la pieza, informó en comunicación personal que las plumas que forman el motivo se encontraban en buen estado, por lo que no fue necesario realizar limpieza o consolidación, siendo únicamente pegada con cera de campeche una esfera de sílica al ojo del águila con el objetivo de darle mayor expresividad, asimismo, se le retiró el marco en el que estaba montada.
} 
De acuerdo con la información proporcionada por la ficha de objeto, los motivos que conforman la composición fueron elaborados con plumas de colibrí, perico, cardenal y garza. En cuanto a la técnica plumajera decimonónica, Teresa Castelló de Yturbide y María Ester Ciancas mencionan el uso de la cera de campeche como adhesivo, aunque no determinan en qué momento pudo haber sustituido al tzauhtli utilizado como pegamento en la técnica prehispánica (Ciancas, 2002). La cera de campeche, al contrario de los mucílagos de orquídea, resultaba de fácil obtención al ser producida por las abejas americanas Melipona beecheii o “jicotes". Posteriormente, tras ser mezclada con propóleos y resinas de árboles (Valadez, 2004, p. 7), adquiría una consistencia pegajosa activable con el calor, suave y maleable4.

Acerca de la ejecución, a diferencia de los mosaicos de pluma que suponía trabajar una superposición de soportes de algodón sin hilar donde se pegaba la pluma formando tiras o fragmentos que después se recortaban al tamaño y a la forma del diseño concebido (Román, 2006, p. 65); en la técnica con cera de campeche se distinguen dos momentos: primero debía dibujarse el motivo en el soporte, luego se enceraba uniformemente la superficie permitiendo visualizar el dibujo; segundo, se comenzaba a emplumar siguiendo un orden establecido por el propio artista. La técnica es de gran complejidad y exige, además de limpieza en la ejecución, la planificación del orden a seguir y la secuencia de colocación de las plumas, pues permite muy poco trabajo de corrección una vez que se están formado las figuras. Otras adecuaciones a la técnica incluyen la integración de estampas litográficas, introducidas en México por Claudio Linati a partir de 1826, a las que se les sobreponían composiciones elaboradas con plumas (Valadez, 2004, p. 8).

En cuanto a la utilización de las plumas para formar los motivos, a diferencia de los mosaicos que empleaban sólo las puntas (Román, 2006, p. 67), José Rodríguez las integró al Emblema nacional de diversas formas, por lo que es posible encontrar tanto puntas como plumas enteras. Por ejemplo, en zonas como las alas del águila es posible apreciar el uso de plumas remeras "en relieve" y cuya forma natural fue aprovechada por el artista, ordenándolas de acuerdo a la posición de los raquis y por tanto, al crecimiento de las barbas. Los motivos fueron construidos en función de sus formas, lo cual es notable por el sentido que toman los raquis de las plumas: si se trata de un objeto circular, las plumas se unieron entre sí en línea curva; si es un objeto vertical, se observan agrupadas de manera lineal. En zonas como las alas y cola del águila, así como en las flechas del carcaj, se distinguen plumas remeras; mientras que en las alas y cola del águila fueron colocadas aprovechando su estructura, en las flechas se recortaron en la punta para darles una terminación bifurcada. Los objetos están claramente delimitados en sus bordes por medio de delicadas líneas formadas por puntas, pero en los fondos y follajes están superpuestas, acomodándose alrededor de los objetos que circundan.

El colorido, de acuerdo con la ficha de objeto, se puede dividir en plumas rojas de cardenal, verdes de perico, blancas de garza y las de tonalidades iridiscentes, de colibrí. Estas últimas, además de formar casi la totalidad del fondo, fueron aprovechadas como puntos de luz colocándolas individualmente en el marco del óvalo y en los ornamentos de los timbales. Las figuras presentan un

\footnotetext{
${ }^{4}$ El uso de la cera de campeche se remonta al periodo prehispánico en el que ya era empleada como material adherente, quemada con copal o para hacer moldes de piezas de metal (Valadez, 2004, p. 7), mientras que a la llegada de los españoles, se utilizó como pulimento, en productos cosméticos y también como adhesivo.
} 
extraordinario trabajo de sombras, luz y profundidad generado a partir del juego de los colores de las plumas. El dorado, probablemente colocado por aplicación a pincel de hoja de oro, se aprecia únicamente en el mango de la espada y las hojas que decoran el gorro frigio[5].

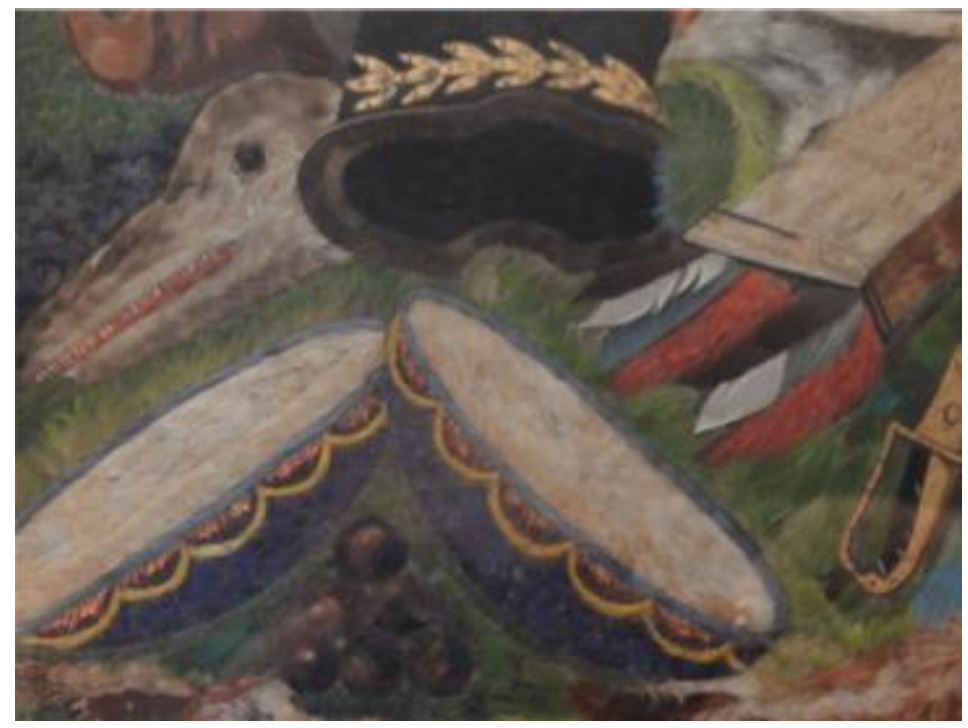

5. Emblema Nacional (detalle), José Rodríguez, 1824.

Plumas sobre cera de campeche, $105 \times 74 \mathrm{~cm}$, Museo Nacional de Antropología, INAH.

\section{Conclusiones}

El acercamiento a la obra de arte plumaria, titulada Emblema Nacional, significó enfrentarse a diversas problemáticas, siendo la principal, la ausencia de documentos que permitieran conocer las condiciones de su ejecución y mayores noticias sobre José Rodríguez, su autor; es por ello que resulta necesario llamar la atención al estudio de la plumaria producida durante el siglo XIX, pues la supervivencia de la técnica - aunque modificada en función de nuevas necesidades - utilizada para plasmar los nuevos iconos y símbolos de la nación republicana forma parte de las manifestaciones que buscaban resaltar a México como una nación liberal.

En cuanto a la apreciación de la técnica, gracias al acercamiento por medio de un ejercicio práctico fue posible comprender cómo el artista trabajó la colocación de las plumas utilizando como adhesivo la cera de campeche, lo que reveló una gran complejidad de ejecución. Si bien la plumaria decimonónica ha sido "desestimada" en relación con el desarrollo tecnológico alcanzado en la técnica prehispánica y novohispana - condición que parece haber relegado su estudio-, el uso de esta cera también posee un elevado nivel de dificultad, pues supone la cuidadosa planeación y preparación de los materiales, ya que se requiere contar con las plumas suficientes para cubrir y formar superficies uniformes que nunca revelen la presencia de la misma.

El Emblema Nacional, como objeto patrimonial, representa en sí mismo la síntesis de la tradición plumaria prehispánica, un ejemplo del complejo proceso de formación de una nueva iconografía, y por último, el uso de la imagen en el México republicano con fines políticos y propagandísticos. Esta extraordinaria pieza reclama su lugar en la Historia del Arte nacional como un ejemplo de la producción artística del convulso siglo XIX mexicano. 


\section{Referencias bibliográficas}

ANÓNIMO (1843), El Museo mexicano, miscelánea pintoresca de amenidades curiosas e instructivas. Tomo Primero, Ignacio Cumplido, Calle de los Rebeldes, México.

ACEVEDO, Esther (2000), "Entre la tradición alegórica y la narrativa factual”, en Los pinceles de la historia: de la patria criolla a la Nación mexicana, Museo Nacional de Arte-BANAMEX Universidad Nacional Autónoma de México - Instituto de Investigaciones Estéticas (UNAM-IIE), México.

BÁEZ MACÍAS, Eduardo (2003), Guía del archivo de la antigua Academia de San Carlos, 1781 1910. UNAM-IIE, México.

CASTELLÓ YTURBIDE, Teresa (1993), “La plumaria en la tradición indígena”, en Arte plumaria en México, Fomento Cultural BANAMEX, México.

CIANCAS, María Esther (2002), Miscelánea de artes aplicadas: siglos XVI al XX, colecciones del Museo Nacional de Historia Castillo de Chapultepec, Plaza y Valdés, México.

CLAVIJERO, Francisco Javier (1826), Historia antigua de México, Tomo I, R. Ackerman, Londres.

FATÁS, Guillermo y BORRÁS, Gonzalo (2006), Diccionario de términos de arte y elementos de arqueología, heráldica y numismática. Alianza Editorial, Madrid.

FLORESCANO, Enrique, “En la época de la reforma”. http://www.jornada.unam.mx/2004/07/15/imaepoca.html

FLORESCANO, Enrique (2006), Imágenes de la patria a través de los siglos, Santillana, México.

ESTRADA DE GERLERO, Elena Isabel (2011), "La plumaria, expresión artística por excelencia”, en Muros, sargas y papeles. Imagen de lo sagrado y lo profano en el arte novohispano del siglo XVI, UNAM-IIE, México.

MACÍAS FLORES, Samira y BLAS ROJAS, Claudia (2012), "Restauración de objetos con plumas en las colecciones del acervo etnográfico del Museo Nacional de Antropología”, en IX Foro académico de ciencia, creación y restauración de la Escuela de Conservación y Restauración de Occidente, Escuela de Conservación y Restauración de Occidente, Guadalajara.

MAGALONI-KERPEL, Diana (2006), "Real and Illusory Feathers: Pigments, Painting Techniques, and the Use of Color in Ancient Mesoamerica", en Nuevo Mundo, Mundos Nuevos, enero.

MORENO GUZMÁN, María Olvido y KORN, Melanie Ruth (2014), “Investigación y conservación bajo presión.Técnicas para el estudio del Penacho del México Antiguo”, en Conservación de Arte Plumario, Publicaciones Digitales Escuela Nacional de Conservación y Museografía - Instituto Nacional de Antropología e Historia (ENCRYM-INAH), México. 
MORENO GUZMÁN, María Olvido (1993), "Las aves y la conservación de la plumaria”, en Arte plumaria en México, Fomento Cultural BANAMEX, México.

NÚÑEZ VÁZQUEZ, Diana María Fernanda (2014), “Caracterización de la Prosthechea citrina”, en Conservación de Arte Plumario, Publicaciones Digitales ENCRYM-INAH, México.

RAMÓN I NAVARRO, Arthur (2011), “Trofeo militar romano (h. 1770). Luis Paret y Alcázar (1746-1799)", en Museo Nacional del Prado, Memoria de Actividades 2010, Ministerio de Cultura, Madrid.

RIPA, Cesare (2007), Iconología, Ediciones Akal, Madrid.

RODRÍGUEZ, C. Emblema Nacional. http://www.mna.inah.gob.mx/coleccion/pieza-2503/fichabasica.html

RODRÍGUEZ DE SAN MIGUEL, Juan Nepomuceno (1839), Pandectas hispano-megicana, tomo I. oficina de Mariano Galván Rivera, México.

ROMÁN TORRES, Rosa Lorena (2006), "Noticias sobre la conservación del mosaico de plumas Cristo Salvador del mundo del Museo Nacional del Virreinato, México", en Nuevo Mundo Mundos Nuevos, febrero.

ROQUE, Georges (1994), "Imágenes e identidades: Europa y América”, en XVII Coloquio Internacional de Historia del Arte. Arte, historia e identidad en América: visiones comparativas. UNAM-IIE, México.

SAHAGÚN, Bernardino de (1829), Historia General de las cosas de Nueva Espela, tomo II, Imprenta Alejandro Valdés, México.

SEBASTIÁN, Santiago (1994), "Los libros de emblemas: uso y difusión en Iberoamérica", en Juegos de ingenio y agudeza: La pintura emblemática de la Nueva España, Museo Nacional de Arte, México.

SERENO AYALA, Yolanda (2013), La magia de las plumas. La voz de Michoacán, Michoacán.

VALADEZ AZÚA, Raúl (2004), "Retomando la apicultura del México antiguo", en Imagen veterinaria, vol. 4, n. ${ }^{\circ}$. 2, abril-junio, UNAM, México. 